\title{
Mycotoxins in Florida Pastures ${ }^{1}$
}

\section{Marcelo Wallau, Brittany Justesen, Ann Blount, Luiz Ferraretto, Glen Aiken, and Aaron Stam²}

\section{Introduction}

Recently, beef cattle producers in Florida have expressed concerns about the potential presence of mycotoxins in summer perennial forages. In other regions of the US, mycotoxins in forage crops have caused productivity and economic losses. Although it is currently a topic of significant interest to the Florida beef industry, there are currently no conclusive data indicating that a problem exists.

The issue of mycotoxins is not new to dairy and swine producers, or to livestock producers in the "fescue belt." Molds in silage or grains and fescue toxicosis have been widely documented in the literature (Gallo et al. 2015; Whitlow and Hagler, Jr. 2017). Aflatoxins and ergot alkaloids are probably the most thoroughly understood and researched mycotoxins. However, there are several other mycotoxins produced by numerous genera of fungi that have different levels of toxicity for animals. Currently, there are still questions about the identification of the toxins and any negative health effects that can be attributed to them. If there are negative impacts to livestock health, how can these effects be prevented or remedied? This fact sheet provides information about the current state of knowledge regarding mycotoxins in Florida perennial grass pastures.

\section{What are mycotoxins?}

Mycotoxins are a broad class of chemical substances (secondary metabolites) produced by filamentous fungi, containing phenolic or alkaloid compounds with varying toxicities to animals. These compounds may be present in forage crops, stored forage, or grains, and develop both pre- and post-harvesting. There are several classes of mycotoxins, with those produced by Claviceps, Alternaria, Fusarium, Aspergillus, Penicillium, Neotyphodium, and Epichloë genera being the most relevant to cattle. The latter is related to fescue toxicosis, which is caused by a group of ergot alkaloids produced by an endophytic, symbiotic fungi on tall fescue. Ergot alkaloids, specifically ergovaline, negatively impact animal performance, but provide benefit to the plant in the form of increased pest resistance and defense against herbivory. The other genera are mostly pathogenic or opportunistic fungi that cause leaf wilting and seed head infection in standing plants, and decompose decaying material or stored grains, silage, and hay. Specific detrimental effects that these toxins can have on animals include reduced intake, vasoconstrictive responses, estrogenic effects, kidney failure, and failure of the central nervous system (Whitlow and Hagler, Jr. 2017). Conversely, not all fungi produce mycotoxins that are known to negatively affect animals. Toxin type, severity and duration of exposure, animal class and physiological stage, and interactions with other toxins and feedstuffs influence the effect.

1. This document is SS-AGR-422, one of a series of the Agronomy Department, UF/IFAS Extension. Original publication date August 2018. Visit the EDIS website at http://edis.ifas.ufl.edu.

2. Marcelo Wallau, assistant professor, forage Extension specialist, Agronomy Department; Brittany Justesen, Extension agent I, UF/IFAS Extension Osceola County; Ann Blount, forage breeder, UF/IFAS North Florida Research and Education Center; Luiz Ferraretto, livestock nutritionist, Department of Animal Sciences; Glen Aiken, center director, UF/IFAS NFREC; and Aaron Stam, Extension agent I, Seminole Tribe of Florida; UF/IFAS Extension, Gainesville, FL 32611.

The Institute of Food and Agricultural Sciences (IFAS) is an Equal Opportunity Institution authorized to provide research, educational information and other services only to individuals and institutions that function with non-discrimination with respect to race, creed, color, religion, age, disability, sex, sexual orientation, marital status, national origin, political opinions or affiliations. For more information on obtaining other UF/IFAS Extension publications, contact your county's UF/IFAS Extension office. 
The incidence of mycotoxins is relatively high in animal feeds and forages. A review by Gallo et al. (2015) reported that over $80 \%$ of samples analyzed contained mycotoxins, especially compounds produced by Fusarium species. The range of concentrations, however, is very broad. Fusarium species are naturally occurring soil fungi that generally infect decaying and prostrate vegetation, particularly during damp and cold weather (Scudamore and Livesey 1998; Gallo et al. 2015). The combination of dormant vegetation and cool, damp weather in the winter can increase the occurrence of Fusarium mycotoxins. Penicillium, Aspergillus, and Alternaria are generally related to molds in silage or hay. Insufficient drying of hay, storage in wet areas, and improper silage preparation where the $\mathrm{pH}$ level is high under aerobic conditions (e.g., loose packing) are conducive to growth of such fungi. Claviceps are responsible for ergot, or sclerotia, affecting seed heads of grasses such as rye, ryegrass, Phalaris spp., Sorghum spp., and some Paspalum spp. The alkaloids produced by Claviceps and the tall fescue endophyte can lead to gangrenous necrosis and a fever that causes a vulnerability to severe heat stress with moderate air temperatures.

Aflatoxins produced by Aspergillus are among the most toxic compounds, with very low threshold limits (between 20 and $100 \mathrm{ppb}$, depending on animal category and possible carryover to animal products). However, it is generally found in energy-rich concentrates (e.g., cereal grains, soybean products, cottonseeds). Such concentrates may also contain other toxins such as fumonisins and zearalenone (ZEA). Fumonisin, deoxynivalenol (DON), 15-acetyl deoxynivalenol, deoxynivalenol-3-glucoside, ZEA, ZEA4-sulfate, and beauvericin are among some of the toxins produced by Fusarium species. Zearalenone is an estrogenic substance. Exposure to high dosages can cause poor reproductive performance in cattle from abortions, reduced conception rates, uterine problems such as cystic ovaries, and secondary issues. In bulls, it can reduce testosterone production and sperm quality. Deoxynivalenol is a group of mycotoxins that can cause vasoconstriction. Because of the restricted blood flow, cattle have difficulty controlling body temperature. Although it is not suspected to cause acute toxicity, it can negatively impact performance through reduced feed consumption. Cattle exposed to high dosages of DON will spend less time grazing and more time in the shade, resulting in weight loss.

The effects of mycotoxins on animal health, especially for ruminants, are inconsistent (Gallo et al. 2015), making it difficult to determine a threshold level. The true dimension of the effects on animal health is poorly understood, but could be related to cattle genetics. One species of fungi can produce several types of toxins; therefore, the isolated effect of one compound versus another is difficult to determine. Furthermore, the interaction between toxins and different feedstuffs, animal breed and physiological stage, and other environmental factors (e.g., air temperature) also affects the response. It is known that ruminants are more tolerant than monogastrics to mycotoxins because the rumen microbiota and feed particles can degrade, deactivate, or bind some of those molecules (Gallo et al. 2015). The effect of mycotoxins also depends on the type of toxins, amount, and duration of exposure.

\section{Mycotoxins in Florida Pastures}

Recently, Gott et al. (2017) surveyed common bermudagrass (Cynodon dactylon) pastures at a single location in south Florida and found 61\% incidence of ZEA, especially during winter sampling. Median ZEA concentrations ranged from 80 to $1100 \mathrm{ppb}$ in August and January, respectively. Common bermudagrass is dormant in the winter and more vulnerable to Fusarium infection due to its decumbent growth habit. Most of these samples, especially those taken during the summer growing season, had concentrations below $250 \mathrm{ppb}$, which is the generally recommended threshold for ZEA (Whitlow and Hagler, Jr. 2017). Conversely, studies reviewed by Gallo et al. (2015) found no negative effects on livestock with mycotoxin concentrations above the threshold suggested by Whitlow and Hagler, Jr. (2017).

A broad effort led by Dr. Ann Blount and UF/IFAS colleagues is examining several other mycotoxins in various forage species at different locations in Florida. Preliminary results from samples sent to the Oregon State University Endophyte Service Laboratory showed the presence of mycotoxins in some of the samples, but with very low concentrations or levels below detection limits. Results are extremely variable, with different concentrations for the same species in different locations. Several mycotoxins were found in samples collected from Florida pastures, and most of them were produced by the Fusarium group (DON, ZEA, 15-acetyl deoxynivalenol, deoxynivalenol-3-glucoside, ZEA-4-sulfate, and beauvericin). The concentration of toxins was extremely variable and dependent upon several factors, including environmental conditions, plant maturity, and stress (e.g., drought, flood, overgrazing, and insect infestation). As previously mentioned, old and dormant stands tend to have higher concentrations of toxins, especially when decaying material is present. Cool and damp weather conditions in the winter favor infestation. 


\section{Conclusion}

Although some analyses showed the presence of mycotoxins in Florida pastures, it is premature to relate these results to any particular problem seen in any class of animal. Mycotoxins are commonly present in forages and other feedstuffs. Their effects on animal performance or health vary and depend upon animal species, class, and physiological stage. The type and concentration of mycotoxins are of greater importance than their presence. Furthermore, mycotoxin problems can be short-lived and seasonal, and may be influenced by many factors ranging from environmental conditions to animal susceptibility. Stressful environmental conditions (e.g., flood or drought) and poor management (e.g., overgrazing and lack of fertilization) increase the susceptibility to pathogens, and, perhaps, the incidence of mycotoxins.

There are many factors, such as supplements that the animals receive, supplement composition, and storage conditions, to consider when analyzing for mycotoxin-related problems. Moldy silage and spoiled hay will likely contain high concentrations of mycotoxins. This is also true for grain-based protein and energy supplements. As mentioned before, mycotoxins in forages are fairly common, and the most important factors are their type and concentration. Feed additives (e.g., binders) may be an alternative to reduce the potential effects of mycotoxins. Research results are promising, but variable; there is no agreement about the efficacy of these additives (Whitlow 2006). Results depend on the type and concentration of mycotoxins, the type and amount of binder, and the animal species (Whitlow 2006; Gallo et al. 2015). It is also important to consider the effects of binders on other nutrients and feed components, such as protein and fiber digestibility and availability.

There are currently no binders that meet all the criteria for sequestering or detoxifying mycotoxins without additional negative effects on animal or diet (Whitlow and Hagler, Jr. 2017). No absorbent product is approved by the Food and Drug Administration (FDA) for prevention or treatment of mycotoxins. Several of those feed additives are used as flow agents and pellet binders, and are generally recognized as safe (GRAS).

At this time, there are no recommended management practices or feed additives for dealing specifically with mycotoxins in pastures, other than for ergot alkaloids in tall fescue (Aiken and Strickland 2013). On the other hand, any practice that reduces stress on pastures will be beneficial to mitigate any fungal disease or infection. The best strategy is to prevent mycotoxin infestation, especially during forage harvesting and processing, and storage of grains, silage, or hay (e.g., proper maturity, harvesting process, compaction and wrapping, storage in dry places). A task force has been formed to determine the incidence and profile of mycotoxins in Florida pastures and identify the conditions associated with high concentrations of those substances. If necessary, a second phase will determine the relationship between the presence of mycotoxins and health-related problems in cattle and other livestock. Research is ongoing to provide more information on these issues.

For more information, contact your local UF/IFAS Extension agent or email Marcelo Wallau at mwallau@ufl.edu.

\section{References}

Aiken, G. E. and J. R. Strickland. 2013. "Forages and Pastures Symposium: Managing the tall fescue-fungal endophyte symbiosis for optimum forage-animal production." J. Anim. Sci. 91: 2369-2378.

Gallo, A., G. Giuberti, J. C. Frisvad, T. Bertuzzi, and K. F. Nielsen. 2015. "Review on mycotoxin issues in ruminants: Occurrence in forages, effects of mycotoxin ingestion on health status and animal performance and practical strategies to counteract their negative effects." Toxins 7(8): 3057-3111.

Gott, P. N., A. Stam, A. Johns, B. G. Miller, B. Bell, T. Jenkins, and G. R. Murugesan. 2017. “039 Mycotoxin survey of common bermudagrass in south-central Florida." J. Anim. Sci. 95(suppl. 4): 19-20.

Scudamore, K. A. and C. T. Livesey. 1998. "Occurrence and significance of mycotoxins in forage crops and silage: a review." J. Sci. Food Agric. 77: 1-17.

Whitlow, L. W. 2006. "Evaluation of mycotoxin binders." In Proceedings of the 4 Mid-Atlantic Nutrition Conference, edited by N. G. Zimmermann. 132-143. College Park, MD: University of Maryland.

Whitlow, L. W. and W. M. Hagler, Jr. 2017. "Mold and mycotoxin issues in dairy cattle: Effects, prevention and treatment." eXtension. Accessed on July 11, 2018. http:// articles.extension.org/pages/11768/mold-and-mycotoxinissues-in-dairy-cattle:-effects-prevention-and-treatment 